\title{
RELATIONSHIP BETWEEN PATIENT'S SATISFACTION OF REMOVABLE DENTURE WEARERS AND ORAL HEALTH-RELATED QUALITY OF LIFE
}

\author{
GUSTI AYU RATIH UTARI MAYUN I ${ }^{1}$, MUSLITA INDRASARI ${ }^{2 *}$, LINDAWATI S KUSDHANY² \\ ${ }^{1}$ Prosthodontics Residency Program, Faculty of Dentistry, Universitas Indonesia, Jakarta, Indonesia. ${ }^{2}$ Departement of Prosthodontics, \\ Faculty of Dentistry, Universitas Indonesia, Jakarta, Indonesia. Email: muslita_tm@yahoo.co.id
}

Received: 16 September 2017, Revised and Accepted: 3 October 2017

\section{ABSTRACT}

Objective: Patient's satisfaction with prosthodontic treatment is affected by many factors. Success of removable denture treatment can be measured using an index to evaluate patients' perceptions of their treatment and their oral health-related quality of life (OHRQOL). To analyze the relationship between patient satisfaction using Turker's patient's perceptions questionnaire and the OHRQoL of removable denture wearers.

Methods: One-hundred and forty removable denture wearers (complete dentures, single complete dentures, and removable partial dentures) participated in this cross-sectional study. Participants were interviewed using a validated Turker's patient's perceptions questionnaire in Indonesia and an OHRQoL questionnaire.

Results: There was a significant relationship between patient's satisfaction and OHRQoL ( $p=0.000)$. Multivariate analysis showed that the duration of using removable dentures had a significant effect on patient's satisfaction using Turker's patient's perceptions questionnaire. The experience of using removable dentures showed a significant effect on OHRQoL.

Conclusion: There was a relationship between patient's satisfaction and their OHRQoL. The duration of using removable dentures affected patient's satisfaction and the experience of using removable dentures affected OHRQoL.

Keywords: Turker's patient's perceptions questionnaires, Oral health-related quality of life index, Removable denture wearers.

(c) 2017 The Authors. Published by Innovare Academic Sciences Pvt Ltd. This is an open access article under the CC BY license (http://creativecommons. org/licenses/by/4. 0/) DOI: http://dx.doi.org/10.22159/ijap.2017.v9s2.41

\section{INTRODUCTION}

The proportion of elderly people in the population increases from year to year and is expected to grow to 1.5 billion by 2050 worldwide [1]. In Indonesia, the number of elderly reached 20.24 million, equivalent to $8.03 \%$ of the total population of Indonesia in 2014, and is expected to continue to increase [2]. Preparation to become an active elder begins before entering the elderly category. Pre-elderly is a period of selfpreparation toward becoming elderly [3].

Recently, there has been a decrease in the number of edentulous populations but with the aging process care for edentulous patients is still needed [4]. Partial or complete loss of teeth may result from physiological or pathological factors [5]. The most common treatment plan for tooth loss in patients is the fabrication of removable dentures, either complete dentures or removable partial dentures. Complete dentures or removable partial dentures can restore the functions of mastication, speech, and esthetics [5]. Due to different socioeconomic backgrounds [6], the fabrication of conventional removable dentures is still the choice of treatment because they are relatively economical, esthetic, and require shorter treatment times and are easier to clean $[7,8]$. Leles et al., as written in the journal by Oh, stated that the cost of treatment is one of the factors influencing a patient's choice of the type of denture he/she wants [9].

The success of prosthodontics treatment should be evaluated by patient satisfaction. Satisfaction is a person's perception that delivers a direct opinion of the treatment received [10]. Turker et al., from the University of Marmara, Istanbul, Turkey, constructed a patient perception index that has been tested for validity and reliability, in the form of a patient satisfaction questionnaire covering various factors related to complete denture care. The questionnaire consists of 11 questions covering six clinical aspects related to successful complete denture care. The six aspects are taste/tasting, ease of chewing, ease of cleaning, comfort, effect of denture on speech, and patient's general satisfaction. Answers to the questionnaire are assessed using a visual analog scale. The first 10 questions use a 7 -point scale, while the $11^{\text {th }}$ question uses a 10 -point scale [11].

Oral and dental health measurements related to the oral health-related quality of life (OHRQOL) have been widely used to assess mouth function and patient well-being. Patient's assessment of treatment satisfaction is generally assessed along OHRQOL. In Indonesia, research on OHRQOL has been conducted by Larasati [12], among others, Larasati's research contained five items/questions including oral cavity function all imitation, physical pain in the form of sharp pain in the teeth and pain when chewing food, psychological discomfort concerning dental problems, and physical and psychological disabilities [12].

The purpose of the current study was to analyze the correlation between patient satisfaction, using Turker's patient's perceptions questionnaire, and OHRQoL. In addition, other factors suspected of contributing to patient's satisfaction with removable denture care, such as sociodemographic factors (age, gender, and education level), experience of a removable denture, duration of removable denture usage, type of removable denture, number of teeth lost, and regions of tooth loss, were also analyzed in relation to patient satisfaction and OHRQoL.

\section{METHODS}

A total of 140 patients, both male and female aged 45 years and over who came to the University Hospital of Dentistry, Universitas Indonesia 
Int J App Pharm, Vol 9, Special Issue 2, 2017

and the University Hospital of Dentistry, University of Trisakti, Indonesia, requiring new complete dentures, single complete dentures, or removable partial dentures were enrolled. All participants were grouped into two age groups according to the WHO classification [13], i.e., $45-59$ years ( 49 subjects) and 60 years and over ( 91 subjects).

Internal consistency of Turker's patient's perceptions questionnaire was assessed by Cronbach's alpha, and convergent validity was assessed by Spearman's correlation test. The convergent validity test of Turker's patient's perceptions questionnaires was made by comparison with the gold standard of the OHRQoL score. All data were then analyzed using a Chi-square test to find a correlation between the sociodemographic factors, the experience of using removable dentures, duration of removable denture usage, type of removable denture, number of teeth lost, and regions of tooth loss with patient satisfaction using Turker's patient's perceptions questionnaire and OHRQoL. Logistic regression was used to determine the most influential risk factors for determining patient satisfaction and OHRQoL.

\section{RESULTS}

The Cronbach's alpha score of Turker's patient's perceptions questionnaire was 0.743 indicating good internal consistency and trustworthiness. The Spearman correlation test outcome was -0.505 indicating that the correlation between the score of Turker's patient's perceptions questionnaire to the OHRQoL score was negative with moderate correlation strength. The correlation between patient satisfaction and OHRQoL was $\mathrm{p}=0.000$, which means the correlation between the two is significant. The results are shown in Table 1.

The correlation between the sociodemographic factors, the experience of using removable dentures, duration of removable denture usage, type of removable denture, number of teeth lost, and regions of tooth loss with patient's satisfaction using Turker's patient's perceptions questionnaires is shown in Table 2.

From the result of the Chi-square test, the experience of removable denture usage $(p=0.047)$ and duration of removable denture usage $(p=0.013)$ was $p<0.05$, and therefore had a significant relationship with patient satisfaction. Gender, education level, experience of using removable dentures, duration of denture usage, and the type of removable denture have $\mathrm{p}<0.25$, which is variable for a multivariate model using logistic regression analysis. The final model of the multivariate analysis showed that the most influential factors for patient satisfaction using Turker's patient's perceptions questionnaires were the duration of removable denture usage (odds ratio $[\mathrm{OR}]=2.470$ ) and gender $(\mathrm{OR}=1.980)$. The results are shown in Table 3.

The next step in the current study was to look at the relationship between patient's satisfaction using Turker's patient's perceptions questionnaire, sociodemographic factors, the experience of removable denture usage, duration of removable denture usage, type of removable denture, regions of tooth loss, and the number of teeth lost with OHRQoL using bivariate analysis using a Chi-square test. The results are shown in Table 4 . The result from final model of the multivariate analysis showed that $76(95.0 \%)$ respondents reported good patient satisfaction and OHRQoL scores and 22 (36.7\%) respondents reported poor patient satisfaction and OHRQoL scores. Patient's satisfaction scores and OHRQoL scores had a value of $\mathrm{p}=0.000$ which indicated a significant relationship. Variable experience of removable denture usage $(p=0.002)$ and type of removable denture $(\mathrm{p}=0.009)$ had a value of $\mathrm{p}<0.05$ indicating a significant relation with OHRQoL. Gender, education level, experience of using removable dentures, duration of removable-denture usage, type of removable denture, regions of tooth loss, and the number of teeth lost had a value of $\mathrm{p}<0.25$, which was variable for the multivariate model using logistic regression analysis. Multivariate test results of OHRQoL are shown in Table 5.
Table 1: Correlation of patient's satisfaction and OHRQoL

\begin{tabular}{ll}
\hline & OHRQoL \\
\hline Patient satisfaction & \\
$\mathrm{R}$ & -0.505 \\
$\mathrm{p}$ & 0.000 \\
$\mathrm{n}$ & 140 \\
\hline
\end{tabular}

Spearman's correlation test. OHRQoL: Oral health-related quality of life

Table 2: Correlation between sociodemographic factors, experience of using removable dentures, duration of removable denture usage, types of removable dentures, regions of tooth loss, and number of teeth lost with patient's satisfaction

\begin{tabular}{|c|c|c|c|}
\hline & \multicolumn{2}{|l|}{ n (\%) } & \multirow[t]{3}{*}{$\mathbf{p}$} \\
\hline & \multicolumn{2}{|c|}{ Patient's satisfaction } & \\
\hline & Good & Poor & \\
\hline \multicolumn{4}{|l|}{ Age } \\
\hline $45-59$ & $25(51.0)$ & $24(49.0)$ & 0.283 \\
\hline$\geq 60$ & $55(60.4)$ & $36(39.6)$ & \\
\hline \multicolumn{4}{|l|}{ Gender } \\
\hline Male & $34(49.3)$ & $35(50.7)$ & $0.064^{* *}$ \\
\hline Female & $46(64.8)$ & $25(35.2)$ & \\
\hline \multicolumn{4}{|l|}{ Education level } \\
\hline Low & $0(0)$ & $0(0)$ & $0.232^{* *}$ \\
\hline Basic & $23(50.0)$ & $23(56.0)$ & \\
\hline High & $57(60.6)$ & 37 (39.4) & \\
\hline \multicolumn{4}{|c|}{ Experience of using denture } \\
\hline Have not used & $23(46.0)$ & $27(54.0)$ & $0.047 *$ \\
\hline Have used & $57(63.3)$ & $33(36.7)$ & \\
\hline \multicolumn{4}{|c|}{$\begin{array}{l}\text { Duration of denture usage } \\
\text { (years) }\end{array}$} \\
\hline $0-3$ & $35(47.3)$ & $39(52.7)$ & $0.013^{*}$ \\
\hline$>3$ & $45(68.2)$ & $21(31.8)$ & \\
\hline \multicolumn{4}{|c|}{ Type of removable denture used } \\
\hline Complete denture & $70(60.3)$ & 46 (39.7) & $0.092^{* *}$ \\
\hline Partial denture & $10(41.7)$ & $14(58.3)$ & \\
\hline \multicolumn{4}{|l|}{ Regions of tooth loss } \\
\hline Anterior & $0(0)$ & $0(0)$ & 1.000 \\
\hline Posterior & $2(50.0)$ & $2(50.0)$ & \\
\hline & $78(57.4)$ & 5842.6 & \\
\hline \multicolumn{4}{|l|}{ Number of teeth lost } \\
\hline$\leq 20$ teeth & $8(47.1)$ & $9(52.9)$ & 0.370 \\
\hline$>20$ teeth & $72(58.5)$ & $51(41.5)$ & \\
\hline
\end{tabular}

Chi-square test. *Significant $(\mathrm{p}<0.05)$ included in the multivariate model.

**Variables for multivariate model

The results of the final model of the multivariate test showed that the most influential factor for OHRQoL was the experience of using removable dentures $(\mathrm{OR}=3.370)$, denture type $(\mathrm{OR}=0.099)$, and patient satisfaction $(\mathrm{OR}=0.035)$.

\section{DISCUSSION}

This study was an analytical study with a cross-sectional design that aimed to analyze the relationship between patient satisfaction and OHRQoL. The study also analyzed the relationship between sociodemographic factors, experience of using removable dentures, duration of removable denture use, removable denture type, number of teeth lost, and tooth loss region with patient satisfaction and OHRQoL.

In the current study, the value of Cronbach's alpha was 0.743 indicating good internal consistency and was acceptable [14]. Turker et al. determined a Cronbach's alpha value of 0.86 in their study [11]. The convergent validity test obtained a value of -0.505 , which showed that the correlation between Turker's patient's perceptions questionnaires and OHRQoL had a negative and moderate correlation; the higher the 
Table 3: Final model of multivariate analysis of patient's satisfaction

\begin{tabular}{|c|c|c|c|c|c|c|c|c|}
\hline \multirow[t]{2}{*}{ Variables } & \multirow[t]{2}{*}{ Coefficient } & \multirow[t]{2}{*}{ SE } & \multirow[t]{2}{*}{ Wald } & \multirow[t]{2}{*}{ Df } & \multirow[t]{2}{*}{$\mathbf{p}$} & \multirow[t]{2}{*}{ OR } & \multicolumn{2}{|l|}{ CI 95\% } \\
\hline & & & & & & & Minimum & Maximum \\
\hline Gender & 0.683 & 0.356 & 3.688 & 1 & 0.055 & 1.980 & 0.986 & 3.975 \\
\hline Time of removable denture usage & 0.904 & 0.358 & 6.371 & 1 & 0.012 & 2.470 & 1.224 & 4.985 \\
\hline Constanta & -1.125 & 0.334 & 11.333 & 1 & 0.001 & 0.325 & & \\
\hline
\end{tabular}

SE: Standard error, OR: Odds ratio, CI: Confidence interval

Table 4: Correlation of patient's satisfaction, sociodemographic factors, experience of denture usage, duration of denture usage, types of removable dentures used, regions of tooth loss, and number of teeth lost with OHRQoL

\begin{tabular}{|c|c|c|c|}
\hline & \multicolumn{2}{|l|}{ n $(\%$} & \multirow[t]{2}{*}{$\mathbf{p}$} \\
\hline & \multicolumn{2}{|c|}{ OHRQoL Good Poor } & \\
\hline \multicolumn{4}{|l|}{ Age } \\
\hline $45-59$ & $41(83.7)$ & $8(16.3)$ & 0.616 \\
\hline$\geq 60$ & $73(80.2)$ & $18(19.8)$ & \\
\hline \multicolumn{4}{|l|}{ Gender } \\
\hline Male & $52(75.4)$ & $17(24.6)$ & $0.069 * *$ \\
\hline Female & $62(87.3)$ & $9(12.7)$ & \\
\hline \multicolumn{4}{|l|}{ Education level } \\
\hline Low & $0(0)$ & $0(0)$ & 0.256 \\
\hline Basic & $35(76.1)$ & $11(23.9)$ & \\
\hline High & $79(84.0)$ & $15(16.0)$ & \\
\hline \multicolumn{4}{|c|}{ Experience of denture usage } \\
\hline Have not used & $34(68.0)$ & $16(32.0)$ & $0.002^{*}$ \\
\hline Have used & $80(88.9)$ & $10(11.1)$ & \\
\hline \multicolumn{4}{|c|}{$\begin{array}{l}\text { Duration of denture usage } \\
\text { (years) }\end{array}$} \\
\hline $0-3$ & $56(75.7)$ & $18(24.3)$ & $0.064 * *$ \\
\hline$>3$ & $58(87.9)$ & $8(12.1)$ & \\
\hline \multicolumn{4}{|c|}{$\begin{array}{l}\text { Types of removable denture } \\
\text { used }\end{array}$} \\
\hline Complete denture & $99(85.3)$ & $17(14.7)$ & $0.009^{*}$ \\
\hline Partial denture & $15(62.5)$ & $9(37.5)$ & \\
\hline \multicolumn{4}{|l|}{ Regions of tooth loss } \\
\hline Anterior & $0(0)$ & $0(0)$ & $0.157 * *$ \\
\hline Posterior & $2(50.0)$ & $2(50.0)$ & \\
\hline Anterior+posterior & $112(82.4)$ & 2418.6) & \\
\hline \multicolumn{4}{|l|}{ Number of teeth lost } \\
\hline$\leq 20$ teeth & $11(64.7)$ & $6(35.3)$ & $0.059 * *$ \\
\hline$>20$ teeth & 103 (83.7) & $20(16.3)$ & \\
\hline \multicolumn{4}{|l|}{ Patient's satisfaction } \\
\hline Satisfied & $76(95.0)$ & $4(5.0)$ & $0.000^{* * *}$ \\
\hline Not satisfied & $38(63.3)$ & $22(36.7)$ & \\
\hline
\end{tabular}

Chi-square test. *Significant $(\mathrm{p}<0.05)$ included in the multivariate model.

**Variables for multivariate model. OHRQoL: Oral health-related quality of life

score of patient satisfaction the lower the score of OHRQoL. The more satisfied the patient was with treatment, the better the OHRQoL score. The correlation between patient satisfaction and OHRQoL was $\mathrm{p}=0.000$, which indicates a significant correlation between the two.

Of the 140 subjects, 76 (95\%) returned good scores in patient satisfaction and OHRQoL. This is consistent with the research conducted by Al-Omiri et al. that showed there was a relationship between patient satisfaction and OHRQoL. According to Al-Omiri et al., patient satisfaction had a positive effect on OHRQoL. This can improve daily life and the perception of dental care [15]. Michaud et al. concluded that patient satisfaction with prosthodontic treatment was associated with OHRQoL.

The ability to chew and mouth condition is a determinant of OHRQoL [10]. Stober et al. also concluded that patient satisfaction and
OHRQoL were significantly associated with complete denture wearers, confirming the importance of prosthodontics treatment for edentulous patients [16].

In the current study, sociodemographic factors had no significant association with patient satisfaction or OHRQoL. Perhaps in this case, individual experiences and differences in cultural backgrounds played a large role. Sociodemographic factors can also influence by differences in attitudes and expectations. Gjengedal et al. stated that older patients will be more accepting of their denture shortcomings because they consider them to be part of their aging process [17], which indicates that patient satisfaction assessments and OHRQoL are subjective.

This result, however, contradicts research conducted by Pan et al. where there was a difference in attitudes of men and women, whereby elderly women had lower satisfaction rates using conventional removable dentures compared to elderly men in the esthetic and ability to chew categories. From previous studies, women are more likely to express their dissatisfaction than men are, especially in terms of esthetics [18]. Other research suggests that men are more able to adapt to their dentures than women are [18]. Regular visits for denture adjustment are more often done by women than men. In addition, physical and psychological factors play a role in satisfaction rates between men and women, one of which is a hormonal factor [18]. Elderly women have a higher risk of bone resorption than elderly men [18]. In elderly women, minerals in the bone, especially in the mandible, decrease with the aging process. Other factors such as osteoporosis also play a role in bone resorption in women [18].

In the current study, there was a significant association between the variables of experience of denture usage and duration of denture usage on patient satisfaction. This was consistent with research conducted by Turker et al. who found that patients who had already used dentures had a higher level of satisfaction than patients who had never used dentures [11]. For variables such as denture type, regions of tooth loss, and number of teeth lost, there was no significant relationship with patient satisfaction. This result is because in this research, more respondents were complete denture wearers with tooth losses in the anterior and posterior regions, and the number of teeth lost was more than 20 .

In the current study, it was found that the most influential factor for patient satisfaction was the duration of removable denture usage and gender. Respondents with $<3$ years of removable denture usage had low degrees of satisfaction compared to subjects with more than 3 years of removable denture usage. This is affected by the patient's ability to adapt to denture usage. This result is in accordance with Engelen et al.'s statement that there was a decrease in oral stereognosis ability (OSA) after maxillary denture insertion because the sensory receptors in the palate are covered by the denture. Engelen et al.'s statement is in line with Amarasena et al.'s statement that patients who have never used a denture before will experience a decrease in OSA 30 minutes after insertion. OSA is the ability of the oral cavity to recognize the shape and texture of food entering the mouth [19]. Men had poorer degrees of satisfaction compared to women [20]. This situation may be explained because women tended to be more dissatisfied with their denture treatment because they are 
Table 5: Final model of multivariate analysis of OHRQoL

\begin{tabular}{|c|c|c|c|c|c|c|c|c|}
\hline \multirow[t]{2}{*}{ Variable } & \multirow[t]{2}{*}{ Coefficient } & \multirow[t]{2}{*}{ SE } & \multirow[t]{2}{*}{ Wald } & \multirow[t]{2}{*}{ Df } & \multirow[t]{2}{*}{$\boldsymbol{P}$} & \multirow[t]{2}{*}{ OR } & \multicolumn{2}{|l|}{ CI 95\% } \\
\hline & & & & & & & Minimum & Maximum \\
\hline Experience of removable denture usage & 1.215 & 0.508 & 5.721 & 1 & 0.17 & 3.370 & 1.245 & 9.118 \\
\hline Patient's satisfaction & -2.190 & 0.594 & 13.595 & 1 & 0.000 & 0.112 & 0.035 & 0.359 \\
\hline Constanta & -0.271 & 0.558 & 0.236 & 1 & 0.627 & 0.763 & & \\
\hline
\end{tabular}

OHRQoL: Oral health-related quality of life

more aware of esthetic factors [20]. However, in other studies, there was no relationship between gender and the satisfaction of removable denture wearers [20].

Factors that most influence OHRQoL were the experience of using removable dentures, the type of denture and the patient's satisfaction. Respondents inexperienced with removable dentures potentially have poor OHRQoL compared to those experienced in using removable dentures. This is associated with the respondent's adaptation to removable dentures. Respondents who already have experience with removable dentures will more quickly adapt to dentures and improve their OHRQoL [21]. Respondents who use complete dentures potentially have poor OHRQoL compared to respondents using partial dentures. The type of removable denture has a small risk factor influencing OHRQoL.

This result is in contrast to research conducted by Bae et al., where partial denture users had decreased OHRQoL compared to complete denture users. This is probably due to different adaptation processes. Complete denture users are more aware of their shortcomings and can function better using a denture because they had previously experienced a transition from partial to complete denture. This is in contrast to partial denture users who have high expectations and may compare their dentures to their original teeth. However, according to Bae et al., there is generally no significant difference in OHRQoL between partial denture wearers and complete denture wearers using oral health impact profile-49 [21]. Respondents with good patient satisfaction scores had a small increased risk of poor OHRQoL compared to respondents with poor patient satisfaction scores. This result was probably due to differences in individual experiences and cultural backgrounds. Patient satisfaction is multifactorial not only involving the patient but also the dentist and technical aspects. The success of denture treatment depends not only on the skills of the dentist but also on the dentist's ability to understand the patient's needs [22]. Theweakness of this research wasthat nore testor reliability test
performed to check for consistency and stability of interpoints correlation of patient satisfaction scores using Turker's patient's perceptions questionnaire. However, the internal consistency of Turker's patient's perceptions questionnaire assessed by Cronbach's alpha resulted in good internal consistency and acceptable results. An unbalanced number of type of removable denture was also a weakness in this study; in this study, more complete denture wearers affected the number of teeth lost and the regions of tooth loss. Another limitation is that objective evaluation of denture quality was omitted considering that the quality of a denture is an important factor that can affect patient satisfaction of removable denture treatment.

\section{CONCLUSIONS}

There was a significant relationship between patient satisfaction and OHRQoL. The duration of removable denture usage was the most influential factor for patient satisfaction, while the experience of removable denture usage was the most influential factor for OHRQoL.

\section{ACKNOWLEDGMENT}

The publication of this manuscript is supported by Universitas Indonesia.

\section{REFERENCES}

1. Brocklehurst PR, Mackay L, Goldthorpe J, Pretty IA. Older people and oral health: Setting a patient-centred research agenda. Gerodontology 2015;32:222-8.

2. Bureau of Central Statistic. In: Susilo D, Chamami A, BHN, editors Statistic of the Elderly. Jakarta: Bureau of Central Statistic; 2015.

3. Petersen PE, Yamamoto T. Improving the oral health of older people: The approach of the WHO global oral health programme. Community Dent Oral Epidemiol 2005;33:81-92.

4. Yamaga E, Sato Y, Minakuchi S. A structural equation model relating oral condition, denture quality, chewing ability, satisfaction, and oral health-related quality of life in complete denture wearers. J Dent 2013;41:710-7.

5. Hobkirk JA, Zarb G. Prosthodontic Treatment for Edentulous Patients: Complete Dentures and Implant Supported-Prostheses. $13^{\text {th }}$ ed. Missouri: Elsevier; 2013

6. Prithviraj DR, Madan V, Harshamayi P, Kumar CG, Vashisht R. A comparison of masticatory efficiency in conventional dentures, implant retained or supported overdentures and implant supported fixed prostheses: A literature review. J Dent Implant 2014;4:153-7.

7. Viola AP, Takamiya AS, Monteiro DR, Barbosa DB. Oral health-related quality of life and satisfaction before and after treatment with complete dentures in a dental school in brazil. J Prosthodont Res 2013;57:36-41.

8. Albaker AM. The oral health-related quality of life in edentulous patients treated with conventional complete dentures. Gerodontology 2013;30:61-6

9. Oh SH, Kim Y, Park JY, Jung YJ, Kim SK, Park SY, et al. Comparison of fixed implant-supported prostheses, removable implant-supported prostheses, and complete dentures: Patient satisfaction and oral healthrelated quality of life. Clin Oral Implants Res 2016;27:e31-7.

10. Michaud PL, de Grandmont P, Feine JS, Emami E. Measuring patientbased outcomes: Is treatment satisfaction associated with oral healthrelated quality of life? J Dent 2012;40:624-31.

11. Turker SB, Sener ID, Ozkan YK. Satisfaction of the complete denture wearers related to various factors. Arch Gerontol Geriatr 2009;49:e126-9.

12. Larasati A. Oral Health Related Quality of Life Index for The Elderly inIndonesia. Thesis. Universitas Indonesia; 2014.

13. Indonesia Health Ministry. Book of Population Data in Health Development Program 2011-2014. ???: Indonesia Health Ministry, Data and Information Center; 2011.

14. Eisinga R, Grotenhuis Mt, Pelzer B. The reliability of a two-item scale: Pearson, cronbach, or spearman-brown? Int J Public Health 2013;58:637-42.

15. Al-Omiri MK, Karasneh J. Relationship between oral health-related quality of life, satisfaction, and personality in patients with prosthetic rehabilitations. J Prosthodont 2010;19:2-9.

16. Stober T, Danner D, Lehmann F, Séché AC, Rammelsberg P, Hassel AJ, et al. Association between patient satisfaction with complete dentures and oral health-related quality of life: Two-year longitudinal assessment. Clin Oral Investig 2012;16:313-8.

17. Gjengedal H, Berg E, Boe OE, Trovik TA. Self-reported oral health and denture satisfaction in partially and completely edentulous patients. Int J Prosthodont 2011;24:9-15.

18. Pan S, Awad M, Thomason JM, Dufresne E, Kobayashi T, Kimoto S, et al. Sex differences in denture satisfaction. J Dent 2008;36:301-8.

19. Amarasena J, Jayasinghe V, Amarasena N, Yamada Y. Oral stereognostic ability during adaptation to new dentures in experienced and 
non-experienced complete denture wearers. J Oral Biosci 2010;52:181-6.

20. Al-Omiri MK, Sghaireen MG, Al-Qudah AA, Hammad OA,

Lynch CD, Lynch E, et al. Relationship between impacts of removable prosthodontic rehabilitation on daily living, satisfaction and personality profiles. J Dent 2014;42:366-72.

21. Bae KH, Kim C, Paik DI, Kim JB. A comparison of oral health related quality of life between complete and partial removable denture-wearing older adults in Korea. J Oral Rehabil 2006;33:317-22.

22. de Siqueira GP, dos Santos MB, dos Santos JF, Marchini L. Patients' expectation and satisfaction with removable dental prosthesis therapy and correlation with patients' evaluation of the dentists. Acta Odontol Scand 2013;71:210-4 